\title{
Aplicación de algún producto notable
}

\section{RICARDO CEDEÑO TOVAR*}

El profesor de matemáticas nos enseña que el binomio $\boldsymbol{x}+\boldsymbol{y}$ elevado al cuadrado es igual al cuadrado del pillmero má́s el doble producto del primero por el segundo, más el cuadrado del segundo, es decir:

$$
(x+y)^{2}=x^{2}+2 x y+y^{2}
$$

Si se profundiza un poco, el profesor nos muestra el cuadrado de lado $x+y$ descompuesto en: dos cuadrades, uno de ellos de lado $x y$ el otro de lado $y$ más dos rectángulos, cada uno de ellos de lados $x$ y $\boldsymbol{y}$. Es decir:
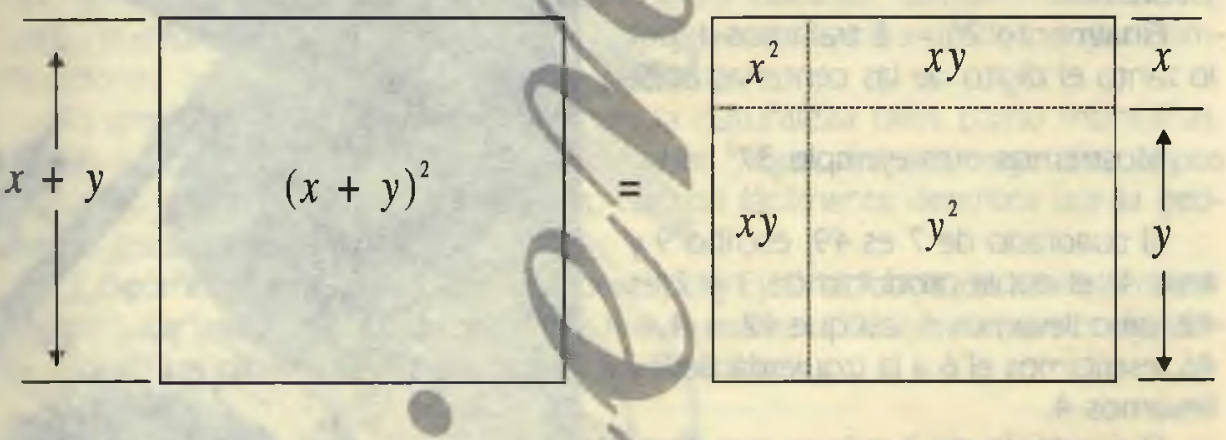

Aunque esta presentación es in vsualy se presenta en la mayoría de los casos, debido al grado de abstracciên ho se entiende.

Presentaré un asidero más concreta y que permite que esto se aprehenda como se aprehenden las tablas de la suma o las tablas de multiplicar.

Si necesitamos saber el resultado de $23^{2}$ podríamos aprovechar lo aprendido en clase, de la siguiente manera. $23=20+3$, así que tengo un binomio. donde: los términos son 20 y 3 . En virtud de (1) tenemos que:

$$
23^{2}=(20+3)^{2}=20^{2}+2 \cdot 20 \cdot 3^{2}=400+120+9=529
$$




\section{0}

Universidad Surcolombiana

Aquí podemos observar que:

1. 20 multiplicado por cualquier otro número, el resultado termina en 0 , es decir que el dígito que corresponde a las unidades es rern

2. $20^{2}$ termina 00 , es decir que los dígitos de las decenas y las unidades son cero cero.

Esto nos permite pensar que en cualquiera de los casos al multiplicar un número por 20 obtengo un espacio, el producido por 0 y que $20^{2}$ genera dos espacios, los producidos por 00.

Así que trataremos de hacer el mismo proceso pero elevando primero el 3. Por lo tanto el dígito de las unidades de $23^{2}$ es 9. para obtener el dígito de las decenas multiplicamos $2 \times 2 \times 3$ y obtenemos 12, así que el dígito es 2 y llevamos 1.

Finalmente $2^{2}=4$ traíamos 1 por lo tanto el dígito de las centenas es 5.

\section{Mostremos otro ejemplo $37^{2}$}

El cuadrado de 7 es 49, escribo $9 y$ llevo 4: el doble producto de 3 y 7 es 42. pero llevamos 4 , así que $42+4=$ 46. escribimos el 6 a la izquierda de 9 y llevamos 4.

El cuadrado de 3 más lo que llevamos son 13. Así que escribimos este resultado a la izquierda de 69 y nos da 1369.

A manera de conclusión volvamos a mirar lo que hemos hecho. Si $N$ es un número de 2 cifras entonces $N=$ $10 a+b$, con a un entero entre 1 y 9 Por tanto:

$$
\begin{gathered}
N^{2}=(10 a+b)^{2}=(10 a)^{2}+ \\
2 .(10 a) \cdot b+b^{2}=100 a^{2}+20 a b+b^{2}
\end{gathered}
$$

Aqui no estoy proponiendo que este sea el método de enseñar y visualizar los productos notables, pero si puede ser un método alternativo: tampoco estoy en contra del uso de la calculadora pero si de que el estudiante tenga en cuenta del porque los resultados.

Esto me parece que son competencias y si queremos profundizar un poco más podríamos pedirle a nuestros estudiantes que propongan un método similar para el caso en que el número sea de tres dígitos.

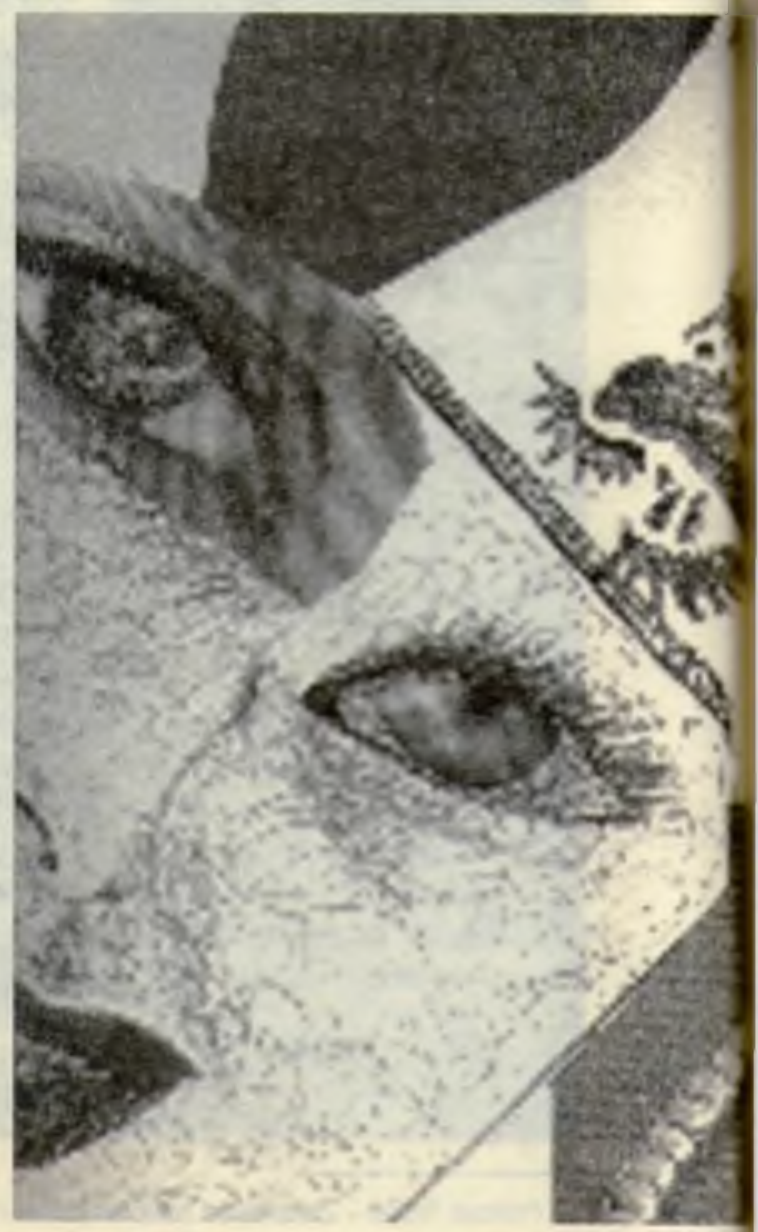

